\title{
Genetic load and transgenic mitigating genes in transgenic Brassica rapa (field mustard) $\times$ Brassica napus (oilseed rape) hybrid populations
}

\author{
Christy W Rose ${ }^{1}$, Reginald J Millwood ${ }^{1}$, Hong S Moon ${ }^{1}$, Murali R Rao ${ }^{1}$, \\ Matthew D Halfhill1,2, Paul L Raymer ${ }^{3}$, Suzanne I Warwick ${ }^{4}$, \\ Hani Al-Ahmad 1,5,6, Jonathan Gressel ${ }^{6}$ and C Neal Stewart Jr*1
}

Address: ${ }^{1}$ Department of Plant Sciences, University of Tennessee, Knoxville, TN 37966 USA, ${ }^{2}$ Department of Biology, St. Ambrose University, Davenport, IA 52803 USA, ${ }^{3}$ Department of Crop and Soil Sciences, University of Georgia, 1109 Experiment Street, Georgia Station, Griffin, GA 30223 USA, ${ }^{4}$ Agriculture and Agri-food Canada, Eastern Cereal and Oilseeds Research Centre, Ottawa, Ontario K1A 0C6, Canada, ${ }^{5}$ Department of Biology \& Biotechnology, An-Najah National University Nablus, Palestine and ${ }^{6}$ Department of Plant Sciences, Weizmann Institute of Science, Rehovot 76100, Israel

Email: Christy W Rose - cweems1@utk.edu; Reginald J Millwood - rmillwood@utk.edu; Hong S Moon - hmoon@utk.edu; Murali R Rao - mraghave@utk.edu; Matthew D Halfhill - halfhillmatthewd@sau.edu; Paul L Raymer - paulraymer@gmail.com; Suzanne I Warwick - warwicks@agr.gc.ca; Hani Al-Ahmad - hani.alahmad@gmail.com; Jonathan Gressel - Jonathan.Gressel@weizmann.ac.il; C Neal Stewart* - nealstewart@utk.edu

* Corresponding author

Published: 31 October 2009

BMC Biotechnology 2009, 9:93 doi:10.1 I86/1472-6750-9-93
Received: II May 2009

Accepted: 31 October 2009

This article is available from: http://www.biomedcentral.com/l472-6750/9/93

(c) 2009 Rose et al; licensee BioMed Central Ltd.

This is an Open Access article distributed under the terms of the Creative Commons Attribution License (http://creativecommons.org/licenses/by/2.0), which permits unrestricted use, distribution, and reproduction in any medium, provided the original work is properly cited.

\begin{abstract}
Background: One theoretical explanation for the relatively poor performance of Brassica rapa (weed) $\times$ Brassica napus (crop) transgenic hybrids suggests that hybridization imparts a negative genetic load. Consequently, in hybrids genetic load could overshadow any benefits of fitness enhancing transgenes and become the limiting factor in transgenic hybrid persistence. Two types of genetic load were analyzed in this study: random/linkage-derived genetic load, and directly incorporated genetic load using a transgenic mitigation (TM) strategy. In order to measure the effects of random genetic load, hybrid productivity (seed yield and biomass) was correlated with crop- and weed-specific AFLP genomic markers. This portion of the study was designed to answer whether or not weed $\times$ transgenic crop hybrids possessing more crop genes were less competitive than hybrids containing fewer crop genes. The effects of directly incorporated genetic load (TM) were analyzed through transgene persistence data. TM strategies are proposed to decrease transgene persistence if gene flow and subsequent transgene introgression to a wild host were to occur.
\end{abstract}

Results: In the absence of interspecific competition, transgenic weed $\times$ crop hybrids benefited from having more crop-specific alleles. There was a positive correlation between performance and number of $B$. napus crop-specific AFLP markers [seed yield vs. marker number $(r=0.54, P=$ $0.0003)$ and vegetative dry biomass vs. marker number $(r=0.44, P=0.005)]$. However under interspecific competition with wheat or more weed-like conditions (i.e. representing a situation where hybrid plants emerge as volunteer weeds in subsequent cropping systems), there was a positive correlation between the number of $B$. rapa weed-specific AFLP markers and seed yield ( $r$ $=0.70, P=0.000 \mathrm{I})$, although no such correlation was detected for vegetative biomass. When 
genetic load was directly incorporated into the hybrid genome, by inserting a fitness-mitigating dwarfing gene that that is beneficial for crops but deleterious for weeds (a transgene mitigation measure), there was a dramatic decrease in the number of transgenic hybrid progeny persisting in the population.

Conclusion: The effects of genetic load of crop and in some situations, weed alleles might be beneficial under certain environmental conditions. However, when genetic load was directly incorporated into transgenic events, e.g., using a TM construct, the number of transgenic hybrids and persistence in weedy genomic backgrounds was significantly decreased.

\section{Background}

Over the past dozen years, a number of crops, such as soybean, maize, rice, cotton and canola, have been genetically engineered to contain a variety of fitness enhancing transgenes. Some of these transgenes can increase a crop's defenses by conferring resistance to a number of diseases, herbicides, abiotic stresses, and yield reducing herbivores [1]. Consequently, there are environmental and regulatory concerns about the adventitious presence of transgenes, especially with regards to hybridization and introgression into weedy relatives [2]. Specifically, could the introgression of fitness-enhancing transgenes result in new hard-to-manage, weedy or invasive biotypes possessing competitive advantages such as herbicide resistance, drought and salt tolerance, or pathogen and insect resistance? If this were to occur, these hybrids could potentially disrupt agricultural and non-agricultural systems [2-16].

Transgene introgression and competition has been studied in many weed $\times$ crop systems including Brassica rapa (field mustard) $\times$ Brassica napus (canola). Halfhill et al. (2005) analyzed the fitness of four B. rapa $\times$ transgenic $B$. napus backcrossed transgenic hybrid lines that originated from a single transgenic event. They found that the average vegetative growth and nitrogen use efficiency of the transgenic hybrids were lower than the wild-type $B$. rapa parent indicating that the transgenic Brassica hybrids would likely be less fit in an agronomic setting. They concluded that the observed decrease in fitness could be the result of species or hybridization effects, initial transgene insertion loci (position effects), ecological conditions, and/or linkage-derived genetic load [6]. Linkage-disequilibrium or genetic load could be one of the main causes of fitness depression witnessed in hybrid and backcrossed generations [6]. Until now, the specific effects of linkagederived genetic load have not been empirically tested under agronomic conditions.

Muller [17] first described genetic load as the total amount of deleterious mutations in the genome of an organism. Since then, genetic load has been studied in the contexts of population and conservation genetics, but not in regards to transgenic plants. Here we define genetic load as the unfavorable consequences of hitchhiking crop or domestication alleles (i.e. crop alleles linked to transgenes) as they become introgressed into a weedy genome $[2,6,18-21]$. Crops have traditionally been bred and selected for domestication traits, such as lack of seed dormancy, reduced seed dispersal, and non-shattering pods, apical dominance, homogenous fruit ripening, reduced competitive ability, and loss of self-incompatibility [2]. In contrast, weeds have been selected for "weediness" traits that are the counterpoint for the crop traits listed above [22]. Therefore, it follows that the incorporation of crop alleles into weedy genetic backgrounds would be disadvantageous for weedy recipients $[2,6,22]$.

The purpose of this study was two-fold. The first objective was to test the hypothesis that genetic load could have a negative effect on introgression and transgene persistence. Specifically, that hybrid inferiority in B. rapa $\times$ B. napus populations could be caused by the genetic load of crop alleles that are inadvertently transferred with the transgene into the genome of the weed host. By measuring Brassica hybrid and parental productivity (seed yield and biomass), under competitive (grown with a wheat crop) and non-competitive field conditions, the first objective was designed to assess the fitness consequences of genetic load in different competitive environments. These fitness data were then correlated with genetic load, as assessed by number of amplified fragment length polymorphism (AFLP) markers specific to the crop parent (B. napus) and to the weed parent (B. rapa), to determine whether weed $x$ crop hybrids with more crop genes were less competitive than hybrids containing fewer crop genes. Our hypothesis was that hybrids possessing more $B$. napus-specific AFLP markers would be less fit under both competitive and non-competitive conditions.

The second objective of this study was to analyze the advantages of utilizing a transgenic-mitigation (TM) strategy (engineered genetic load) to reduce the number or frequency of transgenic progeny under field conditions. A number of gene flow prevention models have been proposed in the literature $[15,23]$. These include: use of buffer zones or barrier crops to block or hinder pollen flow [24], production of male-sterile crop plants to prevent pollen flow [25], insertion of gene-deletor constructs 
(recombinase system that would excise transgenes from pollen grains) [26], insertion of transgenes in "safe" integration sites or areas that are less likely to be transferred during homologous recombination, thereby inhibiting the transgene from being transferred to subsequent generations [27], insertion of transgenes into the maternally inherited plastid genomes $[23,28,29]$, and TM strategies $[16,30-34]$. Of these proposed strategies, TM is a focal point of this study.

Our hypotheses was that direct incorporation of engineered genetic load via TM, would be a stronger mitigator of transgene persistence than random transgene-sitemediated genetic load, which can easily undergo trait segregation in surviving offspring. This is a follow-up field study from greenhouse and shade-house experiments that demonstrated that the above TM strategy was effective in limiting seed production and thereby mitigating transgene flow from $B$. napus to $B$. rapa $[33,34]$. We chose the $\mathrm{BC}_{1} / \mathrm{F}_{2}$ generation since it is the first generation towards introgression in which genetic segregation is expected to vary among transgenic events.

Transgene mitigation is made possible by fusing or linking agronomically beneficial transgenes (i.e. a gene conferring herbicide, insect, or disease-resistance) with transgenes that would decrease the fitness of the weed host, hence inhibiting the persistence of the TM construct. These same weed-mitigating genes are either positive or neutral for the crop $[30,35]$. The mitigating gene used in this study was the $\Delta g a i$ (gibberellic acid insensitive) gene. This gene confers a dwarf phenotype, a principal trait of the Green Revolution. Incorporation of this gene has been shown to increase crop biomass and seed yield, but render weeds less competitive $[33,36]$. The fitness consequences of this engineered genetic load was also estimated in the present study from Brassica hybrid and parental seed yield and above-ground dry biomass measures, under competitive (grown with a wheat crop) and non-competitive field conditions. It was hypothesized that TM would be able to eliminate the persistence of transgenes in progeny and derivative populations, or keep them at exceedingly low frequencies if gene flow and subsequent transgene introgression were to occur.

\section{Results}

\section{Genetic load study}

Productivity data: no competition

When lacking competition, from wheat or weeds, nontransgenic $B$. napus out-performed $B$. rapa and the three hybrid lines (Figures 1A and 1C). The GT5 hybrid line had significantly $(\mathrm{P}<0.01)$ higher seed biomass than B. rapa. The other hybrid lines, GT1 and GT9, were significantly less fit $(\mathrm{P}<0.01)$ than B. rapa. The same pattern was observed for vegetative dry mass. Regardless of treatment or line, there was a strong correlation between biomass and seed yield $(\mathrm{r}=0.83, \mathrm{P}<0.0001)$ (data not shown).

\section{Productivity data: competition with wheat}

When the two non-transgenic parental lines and three GT hybrid lines were grown in competition with wheat, $B$. rapa produced the most, and B. napus and GT9, the fewest seeds (Figure 1D). There were no statistical differences between the GT1 and GT5 hybrid lines for seed production. The GT9 line produced significantly $(\mathrm{P}<0.01)$ fewer seeds than the other hybrid lines and was not significantly different that $B$. napus. However, all of the hybrid lines produced significantly $(\mathrm{P}<0.01)$ fewer seeds than $B$. rapa (Figure 1D) under competitive conditions. Two of the hybrid lines had lower biomass than $B$. rapa, whereas the GT5 hybrid line produced as much biomass as $B$. rapa in competition with wheat (Figure 1B). No statistical differences were observed between non-transgenic $B$. napus and GT1 and GT9 hybrid lines when they were grown in competition with wheat (Figure 1B). The effect of Brassica competition on wheat productivity differed among lines, but overall, no significant difference was observed between wheat growth in the absence of Brassica competition vs. the presence of Brassica competition under the specific conditions of this experiment (data not shown).

\section{AFLP marker analysis}

The five selective primer sets used [18] resulted in a total of 136 B. napus-specific markers. A marker was considered $B$. napus-specific if it was present in the bulked $B$. napus sample and absent in the bulked B. rapa sample. The five selective primer sets also resulted in $95 \mathrm{~B}$. rapa-specific markers. A marker was considered B. rapa-specific if it was present in the bulked $B$. rapa sample and absent in the bulked $B$. napus sample. As the B. rapa-specific markers were absent in the B. napus crop, they can be considered markers of weediness, the more present, the weedier the hybrid or segregant.

The number of B. napus- and B. rapa-specific AFLP markers differed among the GT hybrids and treatments (competition with wheat vs. no-competition with wheat) $(\mathrm{P}>$ 0.0001 ) (Figure 2). In the absence of interspecific competition, GT9 hybrids had significantly more $B$. rapa markers and significantly fewer $B$. napus markers than the other lines. However, when GT9 hybrids were grown in competition with wheat, GT9 had significantly more B. napus markers (actually not different than GT1) and significantly fewer $B$. rapa markers than the other lines in the competition treatment. In contrast, more B. rapa markers were measured in the GT1 hybrids grown in competition with wheat than in GT1 hybrids grown under no competition, while no differences were seen in B. napus markers for either of the treatments. Thus, GT1 and GT9 and different patterns of response to competition with regards of 

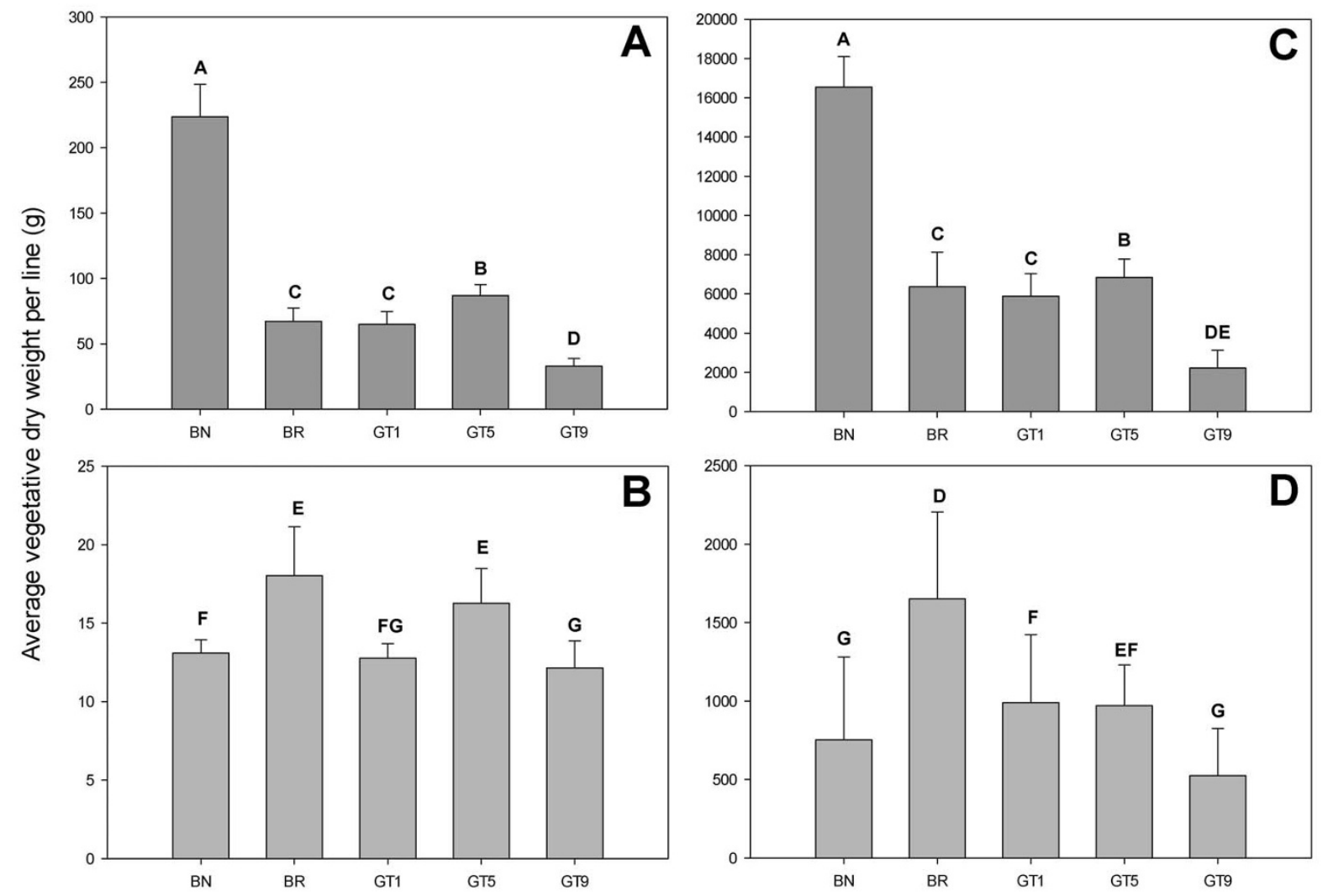

\section{Figure I}

Genetic Load Study: Productivity. Average vegetative dry weight and seed yield $(2 \mathrm{e}+4=20,000$ seeds, $\mathrm{le}+5=100,000$ seeds, etc.) of non-transgenic Brassica napus (BN), Brassica rapa (BR) and transgenic $B C_{1} / F_{2}$ hybrid lines (GTI, GT5 and GT9) grown under non-competitive $(\mathbf{A}$ and $\mathbf{C})$ and competitive field conditions ( $\mathbf{B}$ and $\mathbf{D})$ ). Columns with the same letter do not differ statistically $(P<0.000 I)$. Error bars represent \pm standard error of the means. Note that different $Y$-axis scales are used among figure panels.

genomic constitution. In the GT5 line, there were no significant differences between the number or type of marker in either of the growing conditions (Figure 2). Even though significant differences were observed for the markers and lines under different competitive conditions, correlations were only observed between markers and productivity data for the GT1 hybrids (see below).

\section{B. napus AFLP marker correlation with productivity}

Our hypothesis that hybrids containing more B. napus crop alleles or genetic load would be less competitive than weedy species can be conditionally rejected, but only in the case where there is no interspecific competition (Table $1)$. There was an overall moderate positive correlation between the number of $B$. napus-specific AFLP markers and seed yield and vegetative biomass under non-competitive conditions: for seed yield vs. marker number $(r=0.5$, $\mathrm{P}<0.0003$ ) (Figure 3A) and vegetative dry biomass vs. marker number $(r=0.4, P<0.005$ (Figure 3B). The statis- tical significance can be accounted for by GT1 hybrids (Table 1). No correlations were observed for the other events. When the GT hybrids were grown in competition with wheat, there were no significant correlations between the number of $B$. napus crop markers and seed yield, vegetative dry biomass or with wheat vegetative dry biomass (Table 1). In addition, no correlations between B. napus markers and wheat vegetative dry biomass existed for any of the hybrid lines (Table 1).

\section{B. rapa AFLP marker correlation with productivity}

There were no correlations between the number of $B$. rapa specific AFLP markers and the productivity of the GT hybrids grown alone, i.e., in the absence of interspecific competition (Table 1). Conversely, under competitive conditions (i.e. when the hybrids were grown amongst wheat), there were strong positive correlations between $B$. rapa weediness markers and seed yield but only for the GT1 hybrids. In the GT1 line, the correlations between $B$. 

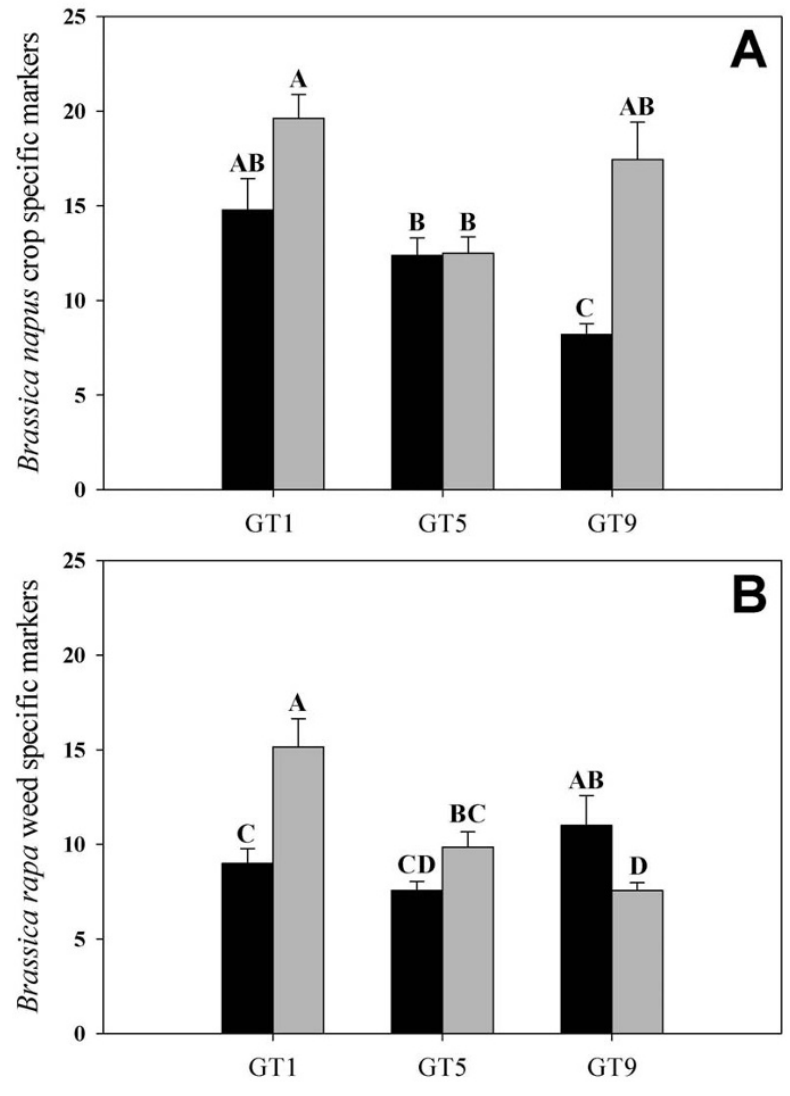

Figure 2

Genetic Load Study: AFLP Markers. (A) Average number of Brassica napus crop-specific- and (B) Average number of Brassica rapa weed-specific AFLP markers in the transgenic $\mathrm{BC}_{1} / \mathrm{F}_{2}$ hybrid (GTI, GT5, GT9) populations as a result of being grown under non-competitive (no-wheat competition plots) (black columns) and interspecific competitive conditions (lines grown in wheat plots) (gray columns). Columns with the same letter do not differ statistically $(\mathrm{P}<$ $0.000 \mathrm{I})$. Error bars represent \pm standard error of the means.

rapa markers under competitive conditions were slightly higher than those for the B. napus markers under no competition: seed yield vs. marker $(\mathrm{r}=0.8, \mathrm{P}<0.0002)$ (Figure $4)$. Overall, the correlations between the number of $B$. rapa markers and seed yield under competitive conditions were significant $(\mathrm{r}=0.7, \mathrm{P}<0.0001)$. No correlations were observed in the GT5 and GT9 hybrid lines with respect to the $B$. rapa markers and seed yield or vegetative dry biomass. In addition, no correlations between $B$. rapa markers and wheat vegetative dry biomass existed for any of the hybrid lines (Table 1).

\section{Transgenic-mitigation study}

Productivity data

For the TM study, we analyzed populations of non-transgenic $B$. napus and $B$. rapa, a transgenic homozygous TM
[TM(H)] B. napus population and transgenic segregating populations of $\mathrm{BC}_{1} / \mathrm{F}_{2}$ hybrids [GT1, GT5, GT9 and TM(B)]. The GT hybrids used in the TM study were the same lines that were analyzed in the genetic load study, whereas the $\mathrm{TM}(\mathrm{H})$ and the $\mathrm{TM}(\mathrm{B})$ lines were unique the TM study. When grown in competition with wheat, the non-transgenic $B$. napus and B. rapa plants reached heights of $130-160 \mathrm{~cm}$ at plant maturity (5 months after planting) whereas the homozygous TM B. napus plants [TM(H)] were only $40-60 \mathrm{~cm}$ at plant maturity. At the time of harvest (early June), the siliques on all of the non-transgenic and hybrid plants were completely mature and ready to shatter, while the siliques on the $\mathrm{TM}(\mathrm{H})$ plants (under competitive and non-competitive conditions) were still green-to-yellow and maturing. Throughout the field season, it was observed that the $\mathrm{TM}(\mathrm{H})$ line had delayed emergence, reduced height, and delayed flowering. However, based on productivity data, when grown alone, the $\mathrm{TM}(\mathrm{H})$ populations performed as well as their non-transgenic crop counterpart (B. napus), indicating that dwarfing could potentially be utilized in true cropping systems without any yield penalties (Figure 5A and 5C). These results are congruent with those of Al-Ahmad et al. (2006a).

When populations of transgenic and non-transgenic segregants of the GT and TM hybrid lines were grown in the absence of competition with wheat, significant $(\mathrm{P}<0.01)$ differences in biomass and seed yield were observed (Figure 5A and 5C), however, all hybrid lines [GT1, GT5, GT9 and TM(B)] performed similarly to $B$. rapa in the absence of competition. In contrast under competitive conditions, there were no statistical differences observed for vegetative biomass (Figure 5B) or seed yield (Figure 5D) for any of the hybrid lines, but there was a great deal of endogenous variation among data in the competition experiment.

\section{Transgene persistence data}

After one field season of natural hybridization among individuals of a hybrid line, the progeny from the $\mathrm{BC}_{1} / \mathrm{F}_{2}$ hybrid lines was comprised of $\mathrm{BC}_{2}$ and $\mathrm{F}_{3}$ individuals. Transgenic segregation ratios in the progeny populations differed among the GT and TM lines (Table 2). The frequencies of transgenic individuals decreased in all GT and TM hybrid progeny populations after one field season. The frequencies of transgenic individuals in these populations differed among lines and under interspecific and intraspecific competitive conditions $(\mathrm{P}>0.0001)$. The proportion of transgenic individuals in the progeny populations of the GT1, GT5, GT9 and TM BC $1 / \mathrm{F}_{2}$ hybrid lines were the same for both non- and competitive conditions (Table 2). However, there was a significant difference observed for the $\mathrm{TM}(\mathrm{H})$ line. The progeny population of the $\mathrm{TM}(\mathrm{H})$ line grown in competition with wheat had fewer transgenic individuals than that grown in the absence of interspecific competition (Table 2). The green 
Table I: Genetic load study: correlation analysis between Brassica napus and Brassica rapa AFLP genomic markers and hybrid productivity.

\begin{tabular}{|c|c|c|c|c|c|}
\hline \multicolumn{6}{|c|}{ Correlation results between Brassica napus crop-specific AFLP markers and hybrid productivity } \\
\hline \multirow[b]{2}{*}{ Line $\left(B_{1} / F_{2}\right)$} & \multicolumn{2}{|c|}{ No Competition } & \multicolumn{3}{|c|}{ Competition } \\
\hline & Seed Yield & Vegetative Biomass & Seed Yield & Vegetative Biomass & Wheat Biomass \\
\hline GT I & $0.6^{*}$ & $0.7^{*}$ & -0.2 & -0.4 & 0.2 \\
\hline GT5 & 0.4 & 0.4 & 0.3 & 0.4 & -0.1 \\
\hline GT9 & 0.1 & -0.01 & -0.5 & -0.4 & 0.1 \\
\hline Global Analysis & $0.5 *$ & $0.4^{*}$ & 0.1 & 0.1 & 0.1 \\
\hline
\end{tabular}

Correlation results between Brassica rapa weed-specific AFLP markers and hybrid productivity

\begin{tabular}{cccccc}
\hline & \multicolumn{2}{c}{ No Competition } & \multicolumn{2}{c}{ Competition } \\
\hline Line $\left(\mathbf{B C} \mathbf{C}_{\mathbf{1}} / \mathbf{F}_{\mathbf{2}}\right)$ & Seed Yield & Vegetative Biomass & Seed Yield & Vegetative Biomass & Wheat Biomass \\
\hline GTI & 0.4 & 0.4 & $0.8^{*}$ & -0.2 & 0.2 \\
GT5 & 0.4 & 0.4 & 0.4 & -0.1 & 0.1 \\
GT9 & 0.3 & -0.1 & 0.3 & 0.1 & $\mathbf{0 . 1}$ \\
\hline Global Analysis & $\mathbf{0 . 1}$ & $\mathbf{0 . 1}$ & $\mathbf{0 . 7}$ & $\mathbf{0 . 1}$ \\
\hline
\end{tabular}

* Denotes significant results $(\mathrm{P}<0.0 \mathrm{I})$

The numeric values represent Pearson correlation coefficients $(r)$.

Hybrids were grown in the presence and absence of interspecific competition with wheat.
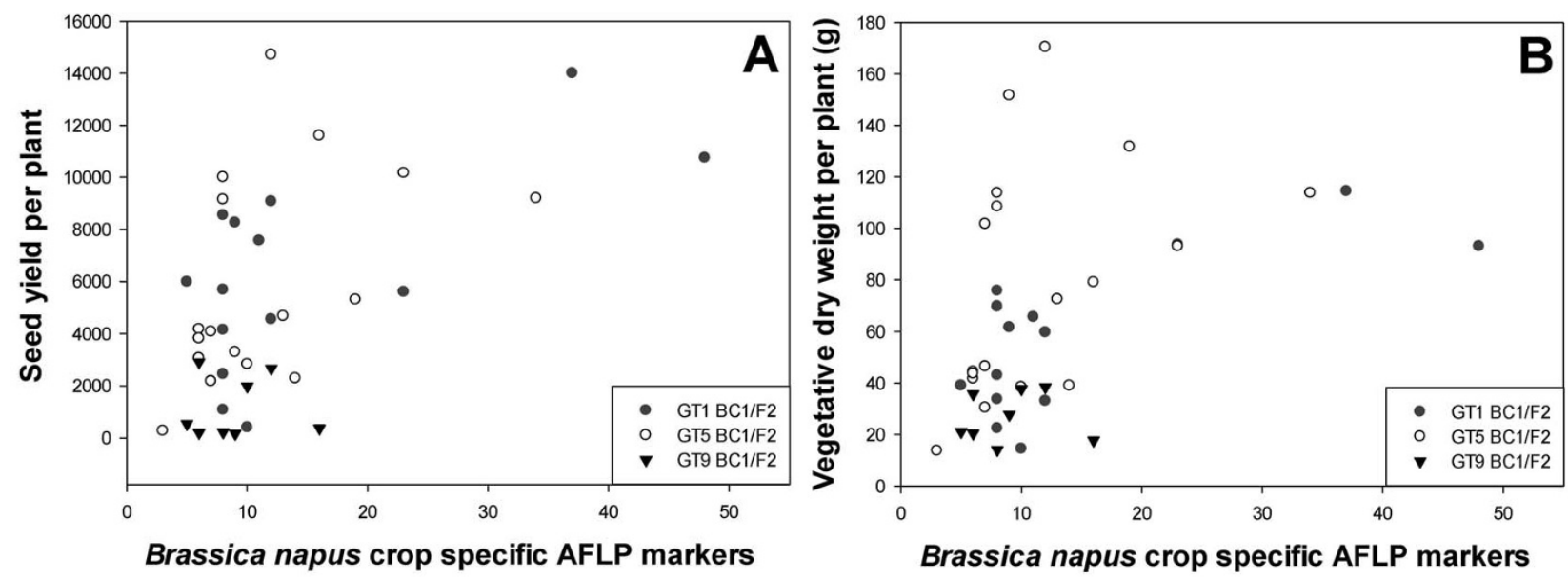

Figure 3

Genetic Load Study: Productivity and B. napus-specific AFLP markers Correlation. Correlation analysis between (A) seed yield $(A)$ (global analysis: $r=0.54, P>0.0003$ ), (B) vegetative dry weight per plant (global analysis: $r=0.44, P>$ 0.0046), and B. napus-specific AFLP markers under non-competitive conditions. Each data point represents an individual plant from the transgenic $\mathrm{BC}_{1} / \mathrm{F}_{2}$ hybrid (GTI, GT5, GT9) populations. 


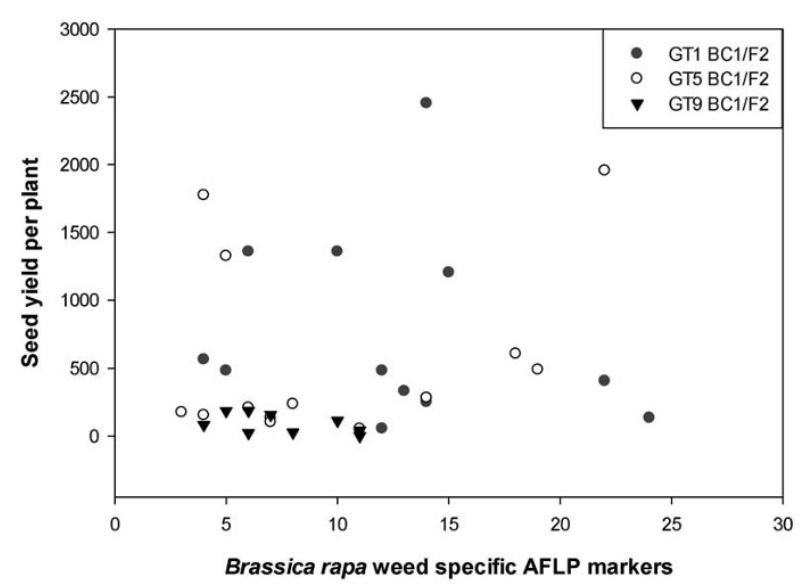

\begin{abstract}
Figure 4
Genetic Load Study: Productivity and B. rapa-specific AFLP markers Correlation. Correlation analysis between seed yield per plant (global analysis: $r=0.70, P>$ $0.000 \mathrm{I}$ ) and B. rapa-specific AFLP markers under competitive conditions. Each data point represents an individual plant from the transgenic $\mathrm{BC}_{1} / \mathrm{F}_{2}$ hybrid (GTI, GT5, GT9) populations.
\end{abstract}

fluorescent marker (GFP) was also detected in the parental (BN and BR) progeny lines indicating the occurrence of gene flow among plots (Table 2 ). The $\mathrm{F}_{1}$ progeny populations for the BN and BR parental lines were not screened on MS medium containing the selecting imazapyr herbicide, Hence, the transgene persistence data reported in Table 2 only applies to gene flow from GT hybrid plots and not TM hybrid or homozygous plots. The decrease in transgenic individuals was greater for the TM hybrid line than the GT lines. The initial frequency of transgenic individuals in the TM hybrid line [TM(B)] was low (22\% of the population), and after one field season, the frequency of transgenic individuals dropped further (i.e. less than $1 \%: 0.03 \%$ in competition and $0.07 \%$ in no competition) (Table 2).

\section{Discussion}

There is growing evidence that many interspecific hybrids between crops and weeds, including transgenic hybrids, have inferior performance compared with their weedy parent (reviewed in [37]), although a few exceptions have been reported $[13,38]$. There are many possible explanations for these observations, most of which focus on the fitness penalties associated with hybridization and backcrossing. A variety of genetic mechanisms can affect hybrid fitness [39]. Heterosis or hybrid vigor could be enhanced by the segregation of additive genetic traits or optimal environmental conditions. In cases where the crop and weedy or wild relative are the same species, there should be fewer genetic barriers to hybrid fitness and transgene persistence $[37,40,41]$. Unless the trait or trans- gene is deleterious, as in the case of TM, hybridization and introgression might easily progress, thereby potentially allowing transgene persistence. This is far more likely to occur with related weeds existing and competing in the same agro-ecosystem as the crop than with wild species, residing in non-agricultural areas where a transgenic trait may have little or no value. The performance of new genotypes introduced via transgenesis and subsequent hybridization are likely also subject to genotype $\times$ environment $(\mathrm{G} \times \mathrm{E})$ interactions [3-7,41-43].

When distantly related taxa hybridize, recombination between homologous or homoeologous chromosomes can result in irregular chromosome pairing. The latter can lead to reduced growth and fertility [37], thus decreasing potential for introgression. In addition, the dilution of weed alleles by crop alleles, i.e., genetic load, might also account for slower introgression regardless of environment $[2,6]$. Our results showed a positive correlation between genetic load (estimated by B. napus-specific AFLP marker numbers) and plant productivity in only one of our transgenic events, GT1, a result congruent with a prior study [6]. No correlation was observed for the other transgenic events suggesting a strong transgenic event or genotype effect. The experimental design allowed the detection of a surprising effect--a counter genetic load finding (i.e. genetic load, conferred by crop alleles, was not detrimental to hybrid performance as originally hypothesized). In our experiments, the number of B. napus crop-specific AFLP markers was associated with an increase in hybrid performance (as opposed to a decrease in performance) in the GT1 hybrids in the absence of interspecific competition with wheat and weeds. Conversely, in the presence of interspecific competition with wheat, there was a strong correlation between $B$. rapa weed-specific AFLP markers and productivity, again, only for the GT1 line. These results indicate a strong $\mathrm{G} \times \mathrm{E}$ interaction and that inherited crop alleles, introgressed as a result of hybridization, can be preferentially selected to ensure maximum growth potential and productivity under crop-favorable conditions (as seen in the absence of interspecific competition). Conversely, inherited weedy alleles can be preferentially selected under more "weed-like" conditions (i.e. under interspecific competitive conditions) [6]. We anticipate that this will continue to occur as the lines continue to backcross.

This evidence of local and situational adaptation demonstrated in our study as well as other studies indicates that many alleles are beneficial in some but not all environments [40-44]. As sessile organisms, plants must be able to maximize resource acquisition; this can be accomplished with adapted genomes. In agriculture and in our study, environmental genomic adaptation could translate to favoring some crop alleles in crops grown in monocultures where weeds are controlled; weed alleles might be 

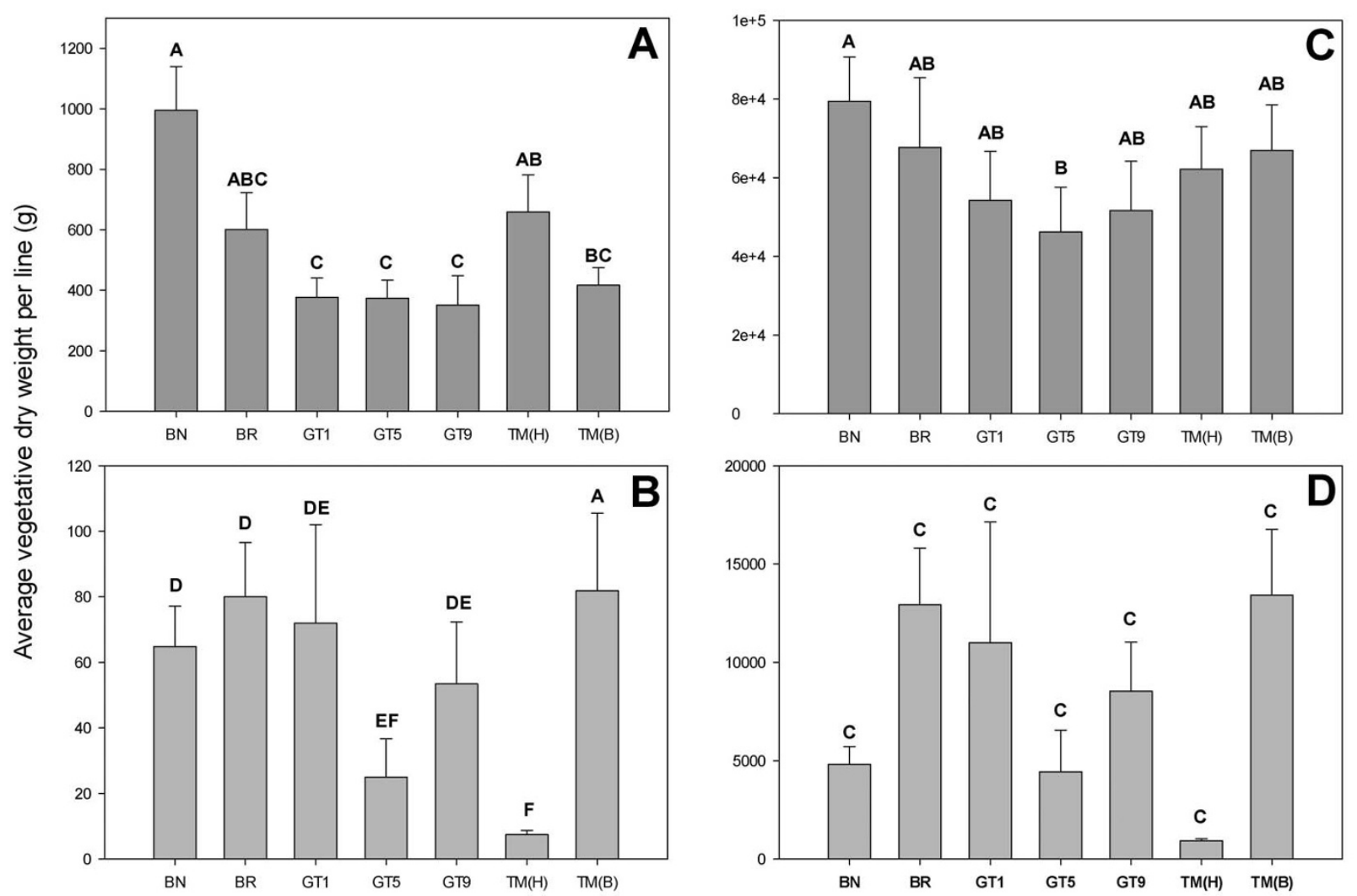

\section{Figure 5}

Transgenic Mitigation Study: Productivity. Average vegetative dry weight and seed yield $(2 e+4=20,000$ seeds, le $+5=$ 100,000 seeds, etc.) of non-transgenic Brassica napus (BN), Brassica rapa $(B R)$, homozygous TM $[T M(H)]$ and transgenic $B C_{1} / F_{2}$ hybrid populations [GTI, GT5, GT9 and TM(B)] being grown under non-competitive (A and C) and competitive field conditions (B and D). Bars with the same letter do not differ statistically $(P<0.000 \mathrm{I})$. Error bars represent \pm standard error of the means. Note that different $Y$-axis scales are used among figure panels.

favored in weeds in competitive environments [22]. Dilution in either direction could be maladaptive. Environmental adaptation and trait selection are further demonstrated in a case-study performed on recombinant inbred sunflower lines [40]. Baack et al. [40] showed that crop traits (earlier flowering time, larger stem diameter, and larger flowering disk diameter) were preferentially favored in one site, while weedy traits (smaller ray and seed size) were favored at another location [40]. These studies indicate that, with regards to genetic load and trait selection, environmentally-dependent selection must be taken into consideration for every transgene, species, and situation studied [40,42-44].

\section{Transgenic event effects and genetic load}

Since transgene insertion is random, the flanking host DNA can differ significantly for individual transgenic events; hence the analysis of multiple events in the present study. Zhu et al. [45] examined the transgene segregation ratios for each of our lines using controlled crosses and progeny analysis. The GT1 and GT5 lines did not deviate from expected Mendelian segregation, indicating homeologous recombination of the transgene locus on an Agenome chromosome (the A genome is shared by the two parental taxa, B napus AACC- and B. rapa AA genomes), and hence the transgene would have a decreased chance of being lost in subsequent backcrossing as a result of genomic incompatibility. Thus, linkage effects could likely cause decreased introgression and genetic load in the GT1 line. Transgenes located on the C-genome of $B$. napus might be subject to greater genomic incompatibility since $B$. rapa does not have the $\mathrm{C}$-genome of $B$. napus. Thus C-genome-localized transgenic events could be an important investigative avenue for decreasing introgression $[2,27]$, although recent research found that homeologous recombination occurs at the same rate as homologous recombination in the $B$. rapa $\times B$. napus system $[29,46]$, suggesting that "safe-integration" sites in $B$. napus are unlikely [46]. 
Table 2: Transgenic mitigation study:percent germination and transgenic segregation frequencies under non-competitive and competitive conditions.

\begin{tabular}{|c|c|c|c|c|c|c|c|c|c|c|c|c|}
\hline \multirow[b]{2}{*}{ Line } & \multicolumn{4}{|c|}{ Parent Populations } & \multicolumn{3}{|c|}{$\begin{array}{l}\text { Progeny Populations: } \\
\text { Competition }\end{array}$} & \multicolumn{5}{|c|}{$\begin{array}{c}\text { Progeny Populations: No } \\
\text { Competition }\end{array}$} \\
\hline & $\begin{array}{l}\text { Seeds } \\
\text { Plated }\end{array}$ & $\begin{array}{c}\text { Germinati } \\
\text { on (\%) }\end{array}$ & $\begin{array}{c}\text { Transgenic } \\
\text { Ratio (\%) }\end{array}$ & MS & $\begin{array}{l}\text { Seeds } \\
\text { Sown }\end{array}$ & $\begin{array}{l}\text { Germinati } \\
\text { on (\%) }\end{array}$ & $\begin{array}{c}\text { Transgenic } \\
\text { Ratio (\%) }\end{array}$ & MS & $\begin{array}{l}\text { Seeds } \\
\text { Sown }\end{array}$ & $\begin{array}{c}\text { Germinati } \\
\text { on (\%) }\end{array}$ & $\begin{array}{c}\text { Transgenic } \\
\text { Ratio (\%) }\end{array}$ & MS \\
\hline BN & 125 & 100 & 0 & $\mathrm{~K}$ & 125 & 93.9 & $\mathrm{I} .4$ & IJ & 125 & 89.1 & 2.8 & $\mathrm{HI}$ \\
\hline BR & 125 & 100 & 0 & K & 125 & 92.2 & 7.3 & G & 125 & 89.8 & 5.7 & $\mathrm{GH}$ \\
\hline GTI & 125 & 80.7 & 55.1 & C & 125 & 89.9 & 38.5 & $\mathrm{D}$ & 125 & 88.6 & 36.8 & D \\
\hline GT5 & 125 & 79.3 & 63.9 & $\mathrm{BC}$ & 125 & 88.9 & 34 & $D$ & 125 & 93.3 & 37.1 & $\mathrm{D}$ \\
\hline GT9 & 125 & 90.7 & 32.1 & $\mathrm{DE}$ & 125 & 90.7 & 10.3 & FG & 125 & 89.8 & 10.4 & FG \\
\hline $\mathrm{TM}(\mathrm{H})$ & 125 & 86.4 & 100 & $A$ & 125 & 81.6 & 77.7 & $A B C$ & 125 & 82.6 & 88.3 & $A B$ \\
\hline TM(B) & 125 & 87.2 & 22.4 & $\mathrm{EF}$ & 125 & 84.3 & 0.4 & $\mathrm{JK}$ & 125 & 87.3 & 0.7 & IJK \\
\hline
\end{tabular}

Percent germination and transgenic frequencies were calculated for the parental $\left(B N\right.$ : $B$. napus; $B R$ : $B$. rapa; $T M(H)$ and hybrid $B C_{1} / F_{2}$ populations (GTI, GT5, GT9, and TM) pre-season and post-harvest. Transgene persistence data reported here only applies to gene flow from GT hybrid plots and not TM hybrid or homozygous plots. Column MS represents transgenic ratio mean separation obtained by Fisher's LSD $(P<0.000 \mathrm{I})$. Data was rank transformed and SAS software was used for data analysis.

\section{Engineered vs. randon transgenic event genetic load}

TM B. napus plants containing the dwarfing gene $\Delta g a i$ were previously analyzed under shade-house conditions [31-34]. Homozygous TM dwarf B. napus plants [TM(H)] grown alone (in the absence of competition) had a much higher seed yield $(\mathrm{P}<0.01)$, and double the shoot and root biomass compared to non-transgenic counterparts ( $P$ $\leq 0.01)$. The $\mathrm{TM}(\mathrm{H})$ line also produced more leaves than tall non-transgenic plants when grown alone at $2.5-\mathrm{cm}$ spacing $(\mathrm{P} \leq 0.05)$ and $10-\mathrm{cm}$ spacing $(\mathrm{P} \leq 0.05)$. However, when grown in competition with tall non-transgenic cohorts, these same plants were exceedingly unfit [33]. The reproductive fitness of TM(H) plants, when grown in competition, was less than $12 \%$, and the harvest index (grain-to-straw ratio) was less than $40 \%$ of that of the non-transgenic $B$. napus competitors. When grown in the absence of competition, the $\mathrm{TM}(\mathrm{H})$ line produced the greatest amount of seeds per plant [33]. From these studies, Al-Ahmad et al. [33] concluded that the $\Delta$ gai gene greatly enhanced seed and biomass yield in a weed-free transgenic crop. However, if dwarfed plants emerged as volunteer weeds and competed with non-transgenic cohorts (and presumably other species), dwarfed plants would be eliminated from poor competitive ability, especially if selective herbicides were not used.

Our field results were congruent with the previous TM research [31-35]. When the homozygous TM line [TM(H)] was grown under agronomic non-competitive conditions, it had equivalent performance as the non-transgenic $B$. napus line with regards to seed yield and biomass. However, under competitive conditions, the TM(H) line produced the least seed and biomass and, hence, performed the poorest of all the lines that were analyzed. In terms of transgene persistence, the transgenic progeny from the backcrossed TM(B) line approached a 50- to 85-fold reduction, under competitive and non-competitive conditions, compared with the 3 -fold reduction in transgene persistence with the non-TM (GT) lines. It must be noted that the final portion of the transgene persistence studies; i.e., germination of seed collected from field grown plants were carried out under optimal growth chamber conditions. This environment did not take into consideration the effects of over-wintering survivorship, dormancy issues or seedling dynamics. Consequently, when environmental factors are considered, one could potentially expect a decrease in performance (germination rates, etc) under realistic field conditions. Hence, ex situ analysis of transgene persistence could appear higher than it actually would be in the field [6]. Regardless, these data do indicate that TM constructs were effective in severely limiting the impact of gene flow from transgenic crops to their wild relatives and transgene persistence. The TM approach could further be enhanced by stacking other weed mitigating transgenes, such as those that prevent seedpods from shattering or those that prevent secondary dormancy. In addition to making plants shorter the dwarfing gene could also confer pleiotropic effects such as altered flowering traits. These could conceivably also have $\mathrm{G} \times \mathrm{E}$ interactions and effect fitness [42]. Depending on the trait, the pleiotropic effect could increase or decrease fitness. In this particular instance, dwarfed plants were very late flowering and also had delayed seed maturation and decreased germination. In this case, the pleiotropic effects would almost certainly decrease introgression.

Some researchers point out that dwarfing in TM is a trait that could foreseeably be selected against in the 
hemizygous state; e.g., in semi-dwarfed plants $[45,46]$. Consequently, the dwarfing allele might not be expressed as highly in first-generation hybrids because of the presence of the dominant GAI allele from the weedy parent genome. Therefore, hybrids containing the TM construct might not have sufficient dwarfing to be selected against in competition, yet harbor the fitness-enhancing gene from the TM construct. In subsequent generations, the deleterious allele would only be expressed in homozygous individuals, which would strongly reduce its capability to decrease fitness. Moreover, if the hybrids are fertile (as is the case for Brassica TM hybrids) [34], this strategy would not prevent them acting as a genetic bridge and pollinating the wild parent [37].

Reuter et al. [47] challenged the theory that dwarfed volunteers or transgenic escapees would be less competitive in feral environments. They noted that feral non-transgenic $B$. napus populations, growing in rural and urban area in northern Germany, were, on average, $41 \%$ shorter than cultivated non-transgenic B. napus. They attributed this height difference to phenotypic adaptation to local environments. Reuter et al. [47] concluded that, under certain environmental and ecological conditions, the proposed mitigation approach (dwarfing) could actually increase escape and persistence of transgenic varieties rather than reducing them, but their study did not consider genotype differences, local adaptation, and environmental effects such as differences in nutrient availability between agronomic and feral conditions. Our transgene persistence data indicate that even if the dwarfing trait is in the semi-dominant state, it is still effective in limiting transgene persistence. Our results indicate that when dwarfing is utilized for a containment strategy, the plants are not able to compete as well and hence persist in subsequent generations. These observations hold true regardless of whether the plants were grown in the presence or absence of interspecific competition. Hence, under the conditions and situations analyzed in this study, hybrids containing TM constructs were not effective weeds.

Different species will likely require various mitigators, and possible also for different environments [16]. Anti-shattering genes will be appropriate for many row crops that have seed shattering weedy relatives, and anti-secondary dormancy genes would be appropriate where weeds possess seed-bank longevity as part of their survival mechanisms. Anti-bolting genes (e.g. anti-kaurene oxidase preventing gibberellic acid biosynthesis) would be appropriate mitigators for biennial crops (carrots, beets) or storage crops (onions, radishes, cabbages) that have weedy relatives. Sterility genes are appropriate for vegetatively propagated species (potatoes, poplars). The waxy transgene in maize would be a good mitigator for pharmaceutical genes expressed in maize embryos, as seeds from self or cross pollination would be shrunken, and unable to survive over-winter in most soils [16]. Thus, to choose an appropriate mitigator for each crop and environment, the researcher must seek out genes that are positive or neutral for the crop in that environment and would be detrimental to the related weedy or wild species.

\section{Conclusion}

There is a paradox regarding the apparent absence of introgression in species where gene flow is expected on the basis of sexual compatibility data. It might be that genetic load of endogenous genes on crop chromosomes moderates introgression, and this same effect could be extended and applied to transgene containment. Perhaps we do not observe extensive transgene persistence in weedy relatives, i.e., only one introgressed transgenic weedy $B$. rapa plant has been observed in the field despite the extensive commercial release of transgenic $B$. napus [20], because of genetic load conferred by the lack of homeologous recombination or hitchhiking of crop alleles. If additional genetic load is imposed using TM, it could dramatically decrease introgression and transgene persistence to an even lower level.

\section{Methods \\ Parental species}

Brassica napus (canola, oilseed rape, OSR) is grown worldwide as an oilseed-producing crop and, after soybean, ranks second in edible oil production. B. napus is an allotetraploid (AACC genome, $2 \mathrm{n}=38$ ) and evolved through hybridization and polyploidization between the two diploid species $B$. rapa $(2 \mathrm{n}=20, \mathrm{AA})$ and $B$. oleracea $(2 \mathrm{n}=18, \mathrm{CC})[29,48]$. B. napus is an excellent model crop for the study of genetic load because it can hybridize with closely related weedy species such as $B$. rapa (field mustard, wild turnip, birdseed rape) [2,4,5,18,19,21,23,27,49-55], Hirschfeldia incana, B.a juncea and, to a lesser degree, with more distant relatives such as Raphanus raphanistrum (wild radish) [[19,56], reviewed in [57]]. However, hybridizations between B. napus and $B$. rapa are the most common and often produce the most viable offspring [57].

B. rapa, is a common weed that can be found in and around many areas of B. napus cultivation. Consequently, $B$. rapa can be a nuisance to farmers because it can compete with and hence reduce the yield of crops such as $B$. napus and wheat $[4,5,18,19,27,52-55,58]$. The presence of weedy $B$. rapa is a major problem in parts of Canada, the US, and in the UK where OSR is grown as a staple crop for oil production [19].

\section{Plants}

Genetic load study

B. napus $\mathrm{cv}$ "Westar' transgenic events were from Halfhill et al. [4]. They contained constitutively-expressed green fluorescent protein (GFP), $m$ GFP5er, and synthetic Bacillus 
thuringiensis (synthetic Bt cry1Ac) under the control of separate $35 \mathrm{~S}$ promoters and contained a kanamycin resistance cassette. These lines were labeled as "GT" lines because they contain GFP and $B \underline{t}$ transgenes. Of the nine independent transgenic events (GT1-9) that were produced by Halfhill et al. [4], we used three (GT1, GT5, and GT9) in both experiments in this study. Sister-hybrid lines, which contain the same transgene construct but in different insertion loci $[6,37,39]$, were produced by hybridization with a single B. rapa accession (acc. 2974) from Quebec, Canada [6] to produce $\mathrm{BC}_{1} / \mathrm{F}_{2}$ populations (see below). Non-transgenic B. rapa (acc. 2974) and $B$. napus (cv Westar) parental lines were used as controls in the genetic load study (Table 3 ).

\section{Transgenic mitigation study}

All of the above-mentioned Brassica lines (B. napus, B. rapa and GT1, GT5 and GT9 $\mathrm{BC}_{1} / \mathrm{F}_{2}$ populations) were utilized along with two additional plant types: $\mathrm{TM} \mathrm{J} 9 \mathrm{~T}_{2} B$. napus [labeled as $\mathrm{TM}(\mathrm{H})$ throughout this manuscript; the " $\mathrm{H}$ " represents homozygous and $\mathrm{TM} \mathrm{BC}_{1} / \mathrm{F}_{2}$ mixed hybrid population (labeled as TM(B) throughout this manuscript, the "B" represents backcross). The transgenic $\mathrm{TM}(\mathrm{H})$ event, i.e. B. napus $\mathrm{cv}$. Westar transformed with a transgene-mitigating (TM) construct, was from Al-Ahmad et al. [33] and served as the control in the present study in comparisons with a TM $\mathrm{BC}_{1} / \mathrm{F}_{2}[\mathrm{TM}(\mathrm{B})]$ mixed hybrid population obtained using the B. rapa accession 2974 described above (Table 3). For this study, all lines were grown under intraspecific (no-competition with wheat, competition within a species) and interspecific (grown amongst wheat, competition with a different species) competition conditions in order to assess the effect of competition on transgene persistence. The TM plants contain the pPZP212-ahas ${ }^{\mathrm{R}}$ - $\Delta g a i-1$ tandem construct that confers ALS (acetolactate synthase)-herbicide resistance and dwarfing. The mitigation gene ( $\Delta g a i)$ used in this study was insensitive to the effects of endogenous and applied
GA $[31,59,60]$. The plants were also kanamycin resistant. The ahas and $\Delta g a i$ genes were tightly linked to each other in the same orientation with a 15-base pair linker sequence [31].

The TM J9 event [33] was selected for our study because of its high productivity compared to three other TM transformants and because it outperformed its non-transgenic $B$. napus counterparts in both greenhouse and shadehouse experiments leading the authors to conclude that this line could potentially be used in future field experiments without any yield penalties [33].

\section{Experimental hybrid populations}

In order to investigate variation in genetic load resulting from different transgenic events, field studies were performed on four genotypically-diverse $B$. napus $\times$ B. rapa hybrid populations. These populations were composed of a mixture of $\mathrm{BC}_{1}$ and $\mathrm{F}_{2}$ individuals. This diverse population type was chosen because it mimics the type of volunteer population that might be found under actual field conditions. Previous research has also shown that Mendelian segregation patterns and the number of crop markers begin to differ among transgenic events in these generations $[6,45]$. Consequently, this population would provide the most power to discriminate genetic load effects among the events. It would also be the generation pool (i.e. post- $\mathrm{F}_{1}$ ) that would yield the highest degree of cropmarker variability $[6,45]$.

Mixed $\mathrm{BC}_{1} / \mathrm{F}_{2}$ populations were produced in the greenhouse. Homozygous GT transgenic $B$. napus lines and the $\mathrm{TM}(\mathrm{H})$ B. napus line were hand-crossed with non-transgenic $B$. rapa to produce $F_{1}$ hybrid lines for each transgenic event. Transgenic $\mathrm{F}_{1}$ hybrids were confirmed for GFP using a hand-held long wave UV light, after which, the $\mathrm{F}_{1}$ hybrids were hand-crossed to Brassica rapa and crossed

Table 3: Plant germplasm.

\begin{tabular}{|c|c|c|c|c|c|}
\hline Line & Experiments & Transgenic? & Generation & Parental Lines & Purpose \\
\hline Brassica napus (BN) & Both & no & $\mathrm{n} / \mathrm{a}$ & $\mathrm{n} / \mathrm{a}$ & crop: parental control \\
\hline Brassica rapa (BR) & Both & no & $\mathrm{n} / \mathrm{a}$ & $\mathrm{n} / \mathrm{a}$ & weed: parental control \\
\hline GTI hybrid & Both & yes: $m G F P 5 e r$ and $B t c r y I A c$ & mixed: $\mathrm{BC}_{1} / \mathrm{F}_{2}$ & $\mathrm{BR}$ and transgenic $\mathrm{BN}$ & $\begin{array}{c}\text { to study event-specific genetic } \\
\text { load }\end{array}$ \\
\hline GT5 hybrid & Both & yes: $m G F P 5 e r$ and $B t$ crylAc & mixed: $B C_{1} / F_{2}$ & $\mathrm{BR}$ and transgenic $\mathrm{BN}$ & $\begin{array}{c}\text { to study event-specific genetic } \\
\text { load }\end{array}$ \\
\hline GT9 hybrid & Both & yes: $m G F P 5 e r$ and $B t$ crylAc & mixed: $B C_{1} / F_{2}$ & $\mathrm{BR}$ and transgenic $\mathrm{BN}$ & $\begin{array}{c}\text { to study event-specific genetic } \\
\text { load }\end{array}$ \\
\hline TM homozygous [TM(H)] & TM only & yes: $\Delta$ gai and ahas & $\mathrm{T}_{2}$ & $\mathrm{BN}$ & TM parental control \\
\hline TM backcross [TM(B)] & TM only & yes: $\Delta$ gai and ahas & mixed: $\mathrm{BC}_{1} / \mathrm{F}_{2}$ & $\mathrm{BR}$ and transgenic $\mathrm{BN}$ & $\begin{array}{l}\text { To study transgene persistence } \\
\text { in a backcrossed population }\end{array}$ \\
\hline
\end{tabular}

Summary of line designations, generations and parental lines for the seven plant germplasm types utilized in this study. The transgene nomenclature is as follows: mGFP5er (gene coding for green fluorescent protein); Bt cry IAc (Bacillus thuringiensis insecticidal toxin gene); $\Delta$ gai (gibberellic acid insensitive gene); ahas (acetolactate synthase-herbicide resistance gene). 
amongst themselves, in order to produce mixed $\mathrm{BC}_{1} / \mathrm{F}_{2}$ populations for each event.

The TM hybrids lack a visual marker and were screened on MS [61] medium containing a discriminatory dose of kanamycin $(260 \mu \mathrm{M})$ and imazapyr $(0.5 \mu \mathrm{M})$ after being surface sterilized [33]. After screening, the $\mathrm{F}_{1} \mathrm{TM}$ plants were transplanted in the greenhouse and then crossed in the same manner as the GT hybrids (described above). The parental and progeny lines were screened under laboratory conditions. The parental seed stocks were screened prior to being sown in the field and the progeny seed stocks were screened post harvest (i.e. transgene persistence data, see below).

\section{Experimental design and data analysis}

Both studies were performed at the Lang Rigdon Research Farm in Tifton, GA, USA $\left(31^{\circ} 27^{\prime} \mathrm{N} 83^{\circ} 30^{\prime} \mathrm{W}\right)$ from October 2007-June 2008. In order to characterize the weediness potential of $\mathrm{BC}_{1} / \mathrm{F}_{2}$ hybrids and their non-transgenic parental lines, individual Brassica plants or populations were grown in conjunction with a fall planted wheat crop (Triticum aestivum, AGS 2000). The hybrids and parental lines were also grown in the absence of interspecific competition to assess their maximum growth and productivity potential. Soil sampling and analysis was performed on the field prior to planting. There were no soil nutrient differences found throughout the field (data not shown). Optimal agronomic practices were followed including fertilizer application, over-head irrigation, and weeding. N$\mathrm{P}-\mathrm{K}$ fertilization was applied at levels recommended to adjust fertility for agronomic wheat production. A $2 \mathrm{~m}$ drill was used to plant the wheat at a seeding rate of $90 \mathrm{~kg}$ per hectare. In the absence of insecticide treatments, plants were subjected to ambient herbivory pressure.

A completely randomized split-plot design with replication was utilized for both portions of this study. Statistical analysis included whole plot treatment and sub-plot interactions. Plant productivity data was analyzed using analysis of variance (ANOVA) using SAS version 9.2 (SAS Institute Inc, Cary, NC, USA). Rank transformation was implemented when the data did not meet equal variance or normality assumptions [62].

In the genetic load study, two-week old Brassica plants were transplanted into the field site two weeks after the wheat was planted (Brassica plants were started in the greenhouse at the same time that the wheat was planted in the field). Prior to transplanting, GFP confirmation was performed using a hand-held long wave UV light. The field site contained twenty plots (ten wheat and ten nowheat plots), fourteen sub-plots within each plot (two replicates for each parental line, three replicates for each hybrid line and one wheat only or blank plot) totaling
280 sub-plots. Sub-plots (lines) and each treatment (wheat: competition/no-competition) were randomized using SAS version 9.2.

In the transgenic mitigation study, all of the above conditions apply except that lines were sown in the field at the time that the wheat was planted instead of being transplanted. Instead of one plant per sub-plot, twenty-five seeds from each line/population were sown (hand-scattered) into $1 \times 2 \mathrm{~m}$ sub-plots. Populations were sown instead of transplanted in order to mimic a volunteer population emerging as weeds in a wheat crop. The field site contained 10 plots ( 5 wheat and 5 no-wheat plots), 7 subplots within each plot (for each of the lines), totaling 70 measurable sub-plots.

At plant maturity (mid-June), Brassica (single plant for the genetic load study or populations for the transgenic mitigation study) above-ground vegetative biomass was handharvested, dried and recorded. Plant dry weight and seed production were used to estimate total productivity. Wheat, located within a half-meter radius surrounding the Brassica plants, was harvested to measure the effects of competition on Brassica and wheat productivity.

\section{Genetic load study: AFLP markers}

AFLP analysis was used to estimate the number of specific alleles from either B. napus or B. rapa in hybrid plants. AFLP analysis was performed as described in Halfhill et al. [18] and Vos et al. [63] with minor modifications. Of the two EcoRI + three primers utilized in Halfhill et al. [18], only the E + AAG selective primer was used in our study. Selective amplification products were analyzed utilizing the CEQ 8000 GenomeLab system (Beckman Coulter, Fullerton, CA, USA). Results were scored utilizing the CEQ AFLP Dominant Scoring Software (bin width: 0.85). $B$. napus-specific markers (i.e., those present within the bulked B. napus sample and absent in the bulked B. rapa sample were selected and scored accordingly, as well as the reverse case for B. rapa-specific markers. Since AFLPs are dominant markers, DNA samples from the parental lines were bulked for analysis for several reasons: (1) to acquire a set of parent-specific markers, (2) to increase discriminatory power, and (3) to eliminate the possibility of false positive marker amplification. The DNA from individuals within the three GT hybrid populations was analyzed by plant. The number of plants sampled per line differed because of tissue availability $[18,20]$. Differences in the total amount of B. napus and B. rapa AFLP markers was analyzed per line and for each treatment by analysis of variance (ANOVA) using SAS version 9.2. Correlations, between AFLP markers and plant productivity data, were analyzed in SAS using the PROC CORR program. SAS macros used in this analysis were kindly provided by Dr. Arnold M. Saxton from the University of Tennessee, 
Knoxville, and can be accessed on the following website http://animalscience.ag.utk.edu/FacultyStaff/ArnoldSax ton.html

\section{Transgenic mitigation study: transgene persistence data} At plant maturity, all of the plants within an individual plot (representing separate segregating GT and TM hybrid populations as well as TM and non-transgenic parental lines) were harvested. Vegetative dry mass and seed yield data were collected (see above). For the GT hybrid and non-transgenic parental lines, a total of 125 seeds ( 5 replicates of 25) were plated on moist filter paper and placed in a growth chamber $\left(16 \mathrm{~h}\right.$ days, $24^{\circ} \mathrm{C}$, and $60 \mu \mathrm{mol} / \mathrm{m}^{2}$ s). After a week, the GT hybrid and parental lines were screened for GFP (green florescent protein) using a handheld long wave UV light. TM lines (hybrids and homozygous parental line) were screened on MS containing kanamycin and imazapyr as above. The germination frequency was calculated by dividing the number of seeds that germinated by the number of seeds ( 25 seeds) that were plated. The transgene persistence frequency was then calculated by dividing the number of transgenic individuals by the number of individual plants that germinated.

\section{Authors' contributions}

CWR: Performed all field and lab-based experiments and data analysis described in this study and drafted the document. RJM: Assisted in the design and field experiment portion of this study. HSM and MRR: Assisted in the field experiment portion of this study as well as data collection and statistical analysis. MDH: Co-conceived of the genetic load portion of this study, and participated in its design and coordination. PLR: Participated in the design and coordination of field experiments, assisted in field experiments, field maintenance and data collection. SIW: Coconceived of the study and helped to revise the manuscript. HA: Developed the TM construct and plants used in this study. Also assisted in editing the manuscript. JG: Conceived of the TM portion of this study, and participated in its design and coordination and helped to revise the manuscript. CNS: PI, conceived of the genetic load portion of this study and participated in its design and coordinated the collaborations that made this study possible; revised the manuscript. All authors read and consented to the final version of the paper.

\section{Acknowledgements}

The authors wish to thank Lewayne White, Jason Burris, Matt Hassey, Laura Abercrombie, Jason Abercrombie, Blake Joyce, Brian Leckie, Ellen Reeve, and Hollis Rice for their assistance in planting, field maintenance, and data collection. We would like to thank Arnold Saxton for providing the SAS macros utilized in this study. We would also like to thank the staff at the University of Georgia Lang-Rigdon Research Facility in Tifton, GA, the staff at the University of Tennessee Institute of Agriculture and the Tennessee Agriculture Experimental Station in Knoxville for facilities and technical support. The USDA Biotechnology Risk Assessment Grant Program funded this research. All research followed USDA-APHIS-BRS regulations.

\section{References}

I. James C: Global Status of Commercialized Biotech/GM Crops: 2007. In ISAAA Brief Volume 37. ISAAA: Ithaca, NY (croplife.intraspin.com/Biotech) .

2. Stewart CN Jr, Halfhill MD, Warwick SI: Transgene introgression from genetically modified crops to their wild relatives. Nature Reviews Genetics 2003, 4:806-8I7.

3. Hails RS, Morley K: Genes invading new populations: a risk assessment perspective. Trends in Ecology and Evolution 2006, 20:245-252.

4. Halfhill MD, Richards HA, Mabon SA, Stewart CN Jr: Expression of GFP and Bt transgenes in Brassica napus and hybridization and introgression with Brassica rapa. Theoretical and Applied Genetics 200I, I03:659-667.

5. Halfhill MD, Zhu B, Warwick SI, Raymer PL, Millwood RJ, Weissinger AK, Stewart CN Jr: Hybridization and backcrossing between transgenic oilseed rape and two related weed species under field conditions. Environmental Biosafety Research 2004, I: 19-28.

6. Halfhill MD, Sutherland J, Moon HS, Poppy G, Warwick SI, Wessinger AK, Rufty TW, Raymer P, Stewart CN Jr: Growth, productivity and competitiveness of introgressed weedy Brassica rapa hybrids selected for the presence of Bt cry IAc and gfp transgenes. Molecular Ecology 2005, I4:3177-3189.

7. Jenczewski E, Ronfort J, Chevre AM: Crop-to-wild gene flow, introgression and possible fitness effects of transgenes. Environmental Biosafety Research 2003, 2:9-24.

8. Légère $A$ : Risks and consequences of gene flow from herbicide-resistant crops: canola (Brassica napus L.) as a case study. Pest Management Science 2005, 6 I:292-300.

9. Chapman MA, Burke JM: Letting the genie out of the bottle: the population genetics of genetically modified crops. New Phytologist 2006, I 70:429-443.

10. Stewart CN Jr, All JN, Raymer PL, Ramachandran S: Increased fitness of transgenic insecticidal rapeseed under insect selection pressure. Molecular Ecology 1997, 6:773-779.

II. Stewart CN Jr, Richards HA, Halfhill MD: Transgenic plants and biosafety: science, misconceptions and public perceptions. BioTechniques 2000, 29:832-843.

12. Pinstrup-Anderson P, Schiøler E: Seeds of Contention. The John Hopkins University Press. Baltimore, Maryland; 2000.

13. Snow AA, Pilson D, Rieseburg LH, Paulsen MJ, Pleskac N, Reagon MR, Wolf DE, Selbo SM: A Bt transgene reduces herbivory and enhances fecundity in wild sunflowers. Ecological Applications 2003, I 3:279-286.

14. Ellstrand NC, Hoffman CA: Hybridization as an avenue for escape of engineered genes. BioScience 1990, 40:438-442.

15. Ellstrand NC: Current knowledge of gene flow in plants: implications for transgene flow. Philosophical transactions of the Royal Society of London. Series B, Biological sciences 2003, 358: I I63-I I 70.

16. Gressel J: Genetic Glass Ceilings - Transgenics for Crop Biodiversity. Johns Hopkins University Press. Baltimore, Maryland; 2008.

17. Muller HJ: Our load of mutations. American Journal of Human Genetics 1950, 2: I II-176.

18. Halfhill MD, Millwood RJ, Weissinger AK, Warwick SI, Stewart CN Jr: Additive transgene expression and genetic introgression in multiple GFP transgenic crop $\times$ weed hybrid generations. Theoretical and Applied Genetics 2003, I 07:1533-I540.

19. Warwick SI, Simard MJ, Légère A, Braun L, Beckie HJ, Mason P, Zhu $B$, Stewart CN Jr: Hybridization between Brassica napus $L$. and its wild relatives: B. rapa L., Raphanus raphanistrum L. and Sinapis arvensis L., and Erucastrum gallicum (Wild.) O.E. Schulz. Theoretical and Applied Genetics 2003, 1 07:528-539.

20. Warwick SI, Légère A, Simard MJ, James T: Do escaped transgenes persist in nature? The case of an herbicide resistance transgene in a weedy Brassica rapa population. Molecular Ecology 2008, I 7:1387-1395.

21. Moon HS, Halfhill MD, Good LL, Raymer PL, Stewart CN Jr: Characterization of directly transformed weedy Brassica rapa and introgressed B. rapa with Bt crylAc and gfp genes. Plant Cell Reports 2007, 26:1001-1010.

22. Warwick SI, Stewart CN Jr: Crops Come from Wild Plants Domestication, Transgenes, and Linkage Together Shape 
Ferality. In Crop Ferality and Volunteerism Edited by: Gressel J. CRC Press, Boca Raton, Florida; 2005:9-30.

23. Daniell $\mathrm{H}$ : Molecular strategies for gene containment in transgenic crops. Nature Biotechnology 2002, 20:58I-586.

24. Kareiva P, Marvier M: Case study 3: Genetically modified organisms: an overview of risk assessment procedures applied to genetically engineered crops. Incorporating science, economics, and sociology in developing sanitary and phytosanitary standards in international trade. In Incorporating Science, Economics, and Sociology in Developing Sanitary and Phytosanitary Standards in International Trade: Proceedings of a Conference: 23 I-246 January 1999; Irving, California Edited by Elaine McGarraugh, National Academy Press; 2000.

25. Mariani C, Debeuckeleer M, Truettner J, Leemans J, Goldberg RB: nduction of male sterility in plants by chimeric ribonuclease gene. Nature 1990, 347:1737-741.

26. Luo $K$, Duan $H$, Zhao D, Zheng $X$, Deng $W$, Chen $Y$, Stewart $C N$ Jr, Richard M, Jiang X, Wu Y, He A, Pei Y, Li Y: 'GM-gene-deletor': fused loxP-FRT recognition sequences dramatically improve the efficiency of FLP or CRE recombinase on transgene excision from pollen and seed of tobacco plants. Plant Biotechnology Journal 2007, 5:263-374.

27. Metz PLJ, Jacobsen E, Nap J-P, Pereira A, Stiekema WJ: The impact of biosafety of the phosphinothricin-tolerance transgene in inter-specific $B$. rapa $\times$ B. napus hybrids and their successive backcrosses. Theoretical and Applied Genetics 1997, 95:442-450.

28. Corriveau JL, Coleman AW: Rapid screening method to detect potential biparental inheritance of plastid DNA and results for over $\mathbf{2 0 0}$ angiosperm species. American Journal of Botany 1988, 75: $1443-\mid 458$

29. Hansen LB, Siegismund HR, Jørgensen RB: Progressive introgression between Brassica napus (oilseed rape) and B. rapa. Heredity 2003, 9I:276-283.

30. Gressel ]: Tandem constructs: preventing the rise of superweeds. Trends in Biotechnology 1999, 17:361-366.

31. Al-Ahmad H, Galili S, Gressel J: Tandem constructs to mitigate transgene persistence: tobacco as a model. Molecular Ecology 2004, | 3:697-7| 0 .

32. Al-Ahmad H, Galili S, Gressel J: Poor competitive fitness of transgenically mitigated tobacco in competition with the wild type in a replacement series. Planta 2005, 222:372-385.

33. Al-Ahmad H, Dwyer J, Moloney M, Gressel J: Mitigation of establishment of Brassica napus transgenes in volunteers using a tandem construct containing a selectively unfit gene. Plant Biotechnology Journal 2006, 4:7-21.

34. Al-Ahmad H, Gressel J: Mitigation using a tandem construct containing a selectively unfit gene precludes establishment of Brassica napus transgenes in hybrids and backcrosses with weedy Brassica rapa. Plant Biotechnology Journal 2006, 4:23-33.

35. Gressel J: Molecular biology of weed control. In Taylor \& Francis, London Johns Hopkins University Press. Baltimore, Maryland; 2002.

36. Gale MD, Youssefian S: Dwarfing genes in wheat. In Progress in Plant Breeding Edited by Russell GE, Butterworths, London; 1 985: I-35.

37. Felber F, Kozlowski G, Arrigo N, Guadagnuolo R: Genetic and ecological consequences of transgene flow to the wild flora. Advances in Biochemical Engineering/Biotechnology 2007, 107:173-205.

38. Guadagnuolo R, Clegg J, Ellstrand NC: Relative fitness of transgenic vs. non-transgenic maize $\times$ teosinte hybrids: a field evaluation. Ecological Applications 2006, 16:1967-74.

39. Burke JM, Rieseberg LH: Fitness effects of transgenic disease resistance in sunflowers. Science 2003, 23: 1250.

40. Baack EJ, Yuval S, Chapman MA, Burke JM, Reiseberg LH: Selection on domestication traits and quantitative trait loci in cropwild sunflower hybrids. Molecular Ecology 2008, 17:666-677.

41. Vacher C, Weis AE, Hermann D, Kossler T, Young C, Hochberg ME: Impact of ecological factors on the initial invasion of $B t$ trangenes into wild populations of birdseed rape (Brassica rapa). Theoretical Applied Genetics 2004, 109:806-8I4.

42. Mercer K, Andow D, Wyse D, Shaw R: Stress and domestication traits increase the relative fitness of crop-wild hybrids in sunflower. Ecology Letters 2007, 10:383-393.

43. Campbell L, Snow A, Ridley C: Weed evolution after crop gene introgression: greater survival and fecundity of hybrids in a new environment. Ecology Letters 2006, 9:1 198-1209.
44. Wright JW, Stanton ML, Scherson R: Local adaptation to serpentine and non-serpentine soils in Collinsia sparsiflora. Evolutionary Ecology Research 2006, 8: I-2I.

45. Zhu B, Lawrence JR, Warwick SI, Mason P, Braun L, Halfhill MD Stewart CN Jr: Inheritance of GFP-Bt transgenes from Brassica napus in backcrosses with three wild $B$. rapa accessions. Environmental Biosafety Research 2004, 3:45-54.

46. Tomiuk J, Hauser TP, Bagger-Jørgensen R: A- or C-chromosomes, does it matter for the transfer of transgenes from Brassica napus. Theoretical Applied Genetics 2000, 100:750-754.

47. Reuter H, Menzel G, Pehlke H, Breckling B: Hazard mitigation or mitigation hazard? Environmental Science and Pollution Research International 2008, 15:529-35.

48. U N: Genomic analysis in Brassica with special reference to the experimental formation of $B$. napus and peculiar mode of fertilization. Japanese Journal of Botany 1935, 7:389-452.

49. Beckie HJ, Seguin-Swartz G, Warwick SI, Johnson E: Multiple herbicide resistant canola (Brassica napus) can be controlled by alternative herbicides. Weed Science 2004, 52:I52-157.

50. Darmency H, Lefol E, Fleury A: Spontaneous hybridizations between oilseed rape and wild radish. Molecular Ecology 1998, 7:1467-I473.

5I. Devos Y, Schrijver A, Reheul D: Quantifying the introgressive hybridization propensity between transgenic oilseed rape and its wild/weedy relatives. Environmental Monitoring and Assessment 2009, 149:303-322.

52. Halfhill MD, Millwood RJ, Raymer PL, Stewart CN Jr: Bt-transgenic oilseed rape hybridization with its weedy relative, Brassica rapa . Environmental Biosafety Research 2002, I:19-28.

53. Jørgensen RB, Andersen $B$ : Spontaneous hybridization between oilseed rape (Brassica napus) and weedy B. campestris (Brassicaceae): a risk of growing genetically modified oilseed rape. American Journal of Botany 1994, 81:1620-1626.

54. Mikkelsen TR, Andersen B, Jørgensen RB: The risk of crop transgene spread. Nature 1996, 380:31.

55. Snow AA, Andersen $B$, Jørgensen RB: Costs of transgenic herbicide resistance introgressed from Brassica napus into weedy B. rapa. Molecular Ecology 1999, 8:605-6I5.

56. Gueritaine G, Sester M, Eber F, Chevre AM, Darmency H: Fitness of backcross six of hybrids between transgenic oilseed rape (Brassica napus) and wild radish (Raphanus raphanistrum). Molecular Ecology 2002, I I: |419-1426.

57. Devos $Y$, Schrijver A, Reheul D: Quantifying the introgressive hybridization propensity between transgenic oilseed rape and its wild/weedy relatives. Environmental Monitoring and Assessment 2009, I49:303-322.

58. Davenport IJ, Wilkinson MJ, Mason DC, Charters YM, Jones AE, Allainguillaume J, Butler HT, Raybould AF: Quantifying gene movement from oilseed rape to its wild relatives using remote sensing. International Journal of Remote Sensing 2000 , 2I:3567-3573.

59. Peng JR, Carol P, Richards DE, King KE, Cowling RJ, Murphy GP, Harberd NP: The Arabidopsis GAI gene defines a signaling pathway the negatively regulates gibberellin responses. Gene Development 1997, I I:3 194-3205.

60. Peng JR, Richards DE, Hartley NM, Murphy GP, Devos KM: 'Green revolution' genes encode mutant gibberellin response modulators. Nature 1999, 400:256-6I.

6I. Murashige T, Skoog F: A revised medium for rapid growth and bioassays with tobacco tissue cultures. Physiologia Plantarum 1962, 15:473-497.

62. Ott RL, Longnecker M: An Introduction to Statistical Methods and Data Analysis. 5th edition. Duxbury Thompson Learning, Pacific Grove, California; 2001 .

63. Vos P, Hogers R, Bleeker M, Reijans M, Lee T van de, Hornes M, Frijter A, Pot J, Peleman J, Kuiper M, Zabeau M: AFLP: a new technique for DNA fingerprinting. Nucleic Acids Research 1995 , 23:4407-44I4. 